\title{
The value of serum precipitins against specific antigens in patients diagnosed with hypersensitivity pneumonitis - retrospective study
}

\author{
MONIKA SZTURMOWICZI, BARBARA GARCZEWSKA², MAEGORZATA E. JĘDRYCH', \\ IWONA BARTOSZUK ${ }^{1}$, MAEGORZATA SOBIECKA ${ }^{l}$, WITOLD TOMKOWSKI', \\ EWA AUGUSTYNOWICZ-KOPEC $C^{2}$ \\ ${ }^{1}$ I Department of Lung Diseases, National Institute of Tuberculosis and Lung Diseases, Warsaw, Poland \\ ${ }^{2}$ Department of Microbiology, National Institute of Tuberculosis and Lung Diseases, Warsaw, Poland
}

\begin{abstract}
Introduction: Hypersensitivity pneumonitis $(H P)$ is the third most common interstitial lung disease, and is often under-recognized, especially in patients who are not aware of their occupational or environmental contact with organic antigens. The aim of the present study was to assess the results of serum specific IgG antibodies (ssIgG) in HP patients and their correlation with clinical data.

Material and methods: $128 \mathrm{HP}$ patients, median age 53 years, participated in the study. The control group consisted of 102 patients with interstitial lung diseases (ILDs) other than HP. Assessment of pretreatment ssIgG to thermophilic actinomycetes and protein antigens from bird droppings (pigeons, hens, ducks, parrots, turkeys) was performed by double diffusion in agar gel according to Ouchterlony method.

Results: Positive precipitins were obtained in 57\% of all HP patients and in $61 \%$ of those exposed to above mentioned antigens. Positive results in the control group were obtained in $7 \%$ of patients. Sensitivity of ssIgG in HP group was 0.57 and specificity 0.93. Precipitins to at least one bird antigen was confirmed in $64 \%$ of HP patients exposed to birds. Precipitins to thermophilic bacteria were found in $29 \%$ of HP patients exposed to hay or hay products.

Conclusions: The results of the study indicate that ssIgG against birds' allergens were the valuable diagnostic tool in HP patients. Low-rate of confirmation of ssIgG to thermophilic bacteria in patients exposed to hay or hay products indicate that other microorganisms, most likely molds, could be responsible for the disease development.
\end{abstract}

Key words: hypersensitivity pneumonitis, precipitins, farmer's lung, birds' keepers lung.

(Centr Eur J Immunol 2019; 44 (4): 390-394)

\section{Introduction}

Hypersensitivity pneumonitis (HP) is an interstitial lung disease caused by exaggerated immune response to inhalation of various organic antigens. HP constitutes the third most common interstitial lung disease (after idiopathic lung fibrosis and interstitial lung disease in the course of collagen tissue disease) $[1,2]$. The annual incidence rate of HP is estimated at $0.9-1.8$ per 100,000 $[1,3,4]$. Clinical diagnostic algorithm of HP, proposed recently by Vasakova et al. [5], takes into account three diagnostic criteria:
1. Signs and symptoms of pulmonary disease in the persons with repeated occupational or environmental exposure to specific, mostly organic, antigens, +/- the presence of serum specific IgG antibodies.

2. Radiological signs of interstitial lung disease (ILD) described on high resolution chest computed tomography (HRCT), with characteristic features such as: ill-defined centrilobular nodules, mosaic lung attenuation composed of areas of ground glass opacities and air-trapping, and the predominance of attenuations in the upper parts of the lungs [6].

Correspondence: Prof. Monika Szturmowicz, I Department of Lung Diseases, National Institute of Tuberculosis and Lung Diseases, 26 Płocka St., 01-138 Warsaw, Poland, e-mail: monika.szturmowicz@ gmail.com Submitted: 3.05.2019; Accepted: 14.08.2019 


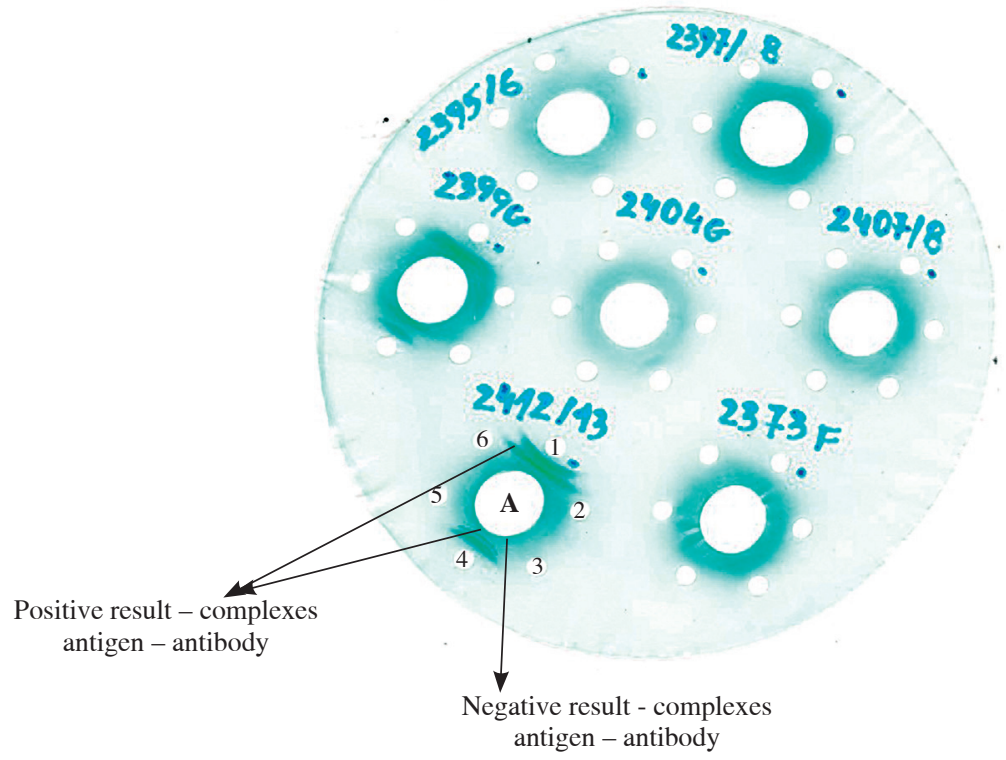

1 - Antigens from pigeon droppings -

positive result

2 - Antigens from hen faeces

3 - Antigens from duck droppings

4 - Antigens from parrot droppings -

positive result

5 - Antigens from turkey droppings

6 - Mix antigens thermophilic

actinomycetes (Ervinia herbicola,

Thermoactinomyces vulgaris,

Thermopolyspora polyspora)

A - tested serum

Fig. 1. The results of precipitation test with thermophilic actinomycetes and with protein antigens of birds' droppings

3. Lymphocytosis in bronchoalveolar lavage (BAL), exceeding $30 \%$, in most patients $[7,8]$.

Lung biopsy, for confirmation of HP, is suggested in patients who do not fulfil the above mentioned criteria. The histologic features of HP consist of inflammatory lymphocytoplasmatic infiltrations with bronchiolocentric distribution, the presence of poorly formed granulomas, and negative cultures for acid-fast bacilli and fungi [9].

Specific serum IgG antibodies (ssIgG) to various avian proteins, bacterial compounds, or molds may be assessed in serum or BAL in the HP diagnostic pathway [10]. Precipitation, Ouchterlony double diffusion, or immunoelectrophoresis are used for qualitative determination of antibodies [10]. ELISA, ImmunoCAP and Immulite tests enable quantitative determination of $\operatorname{ss} \operatorname{IgG}[10]$.

The aim of the present retrospective study was to assess the results of ssIgG evaluation in HP patients and their correlation with clinical data.

\section{Material and methods}

128 patients, 65 females, 63 males, median age 53 years (range, 18-75 years), with HP recognized in the period of 2005-2015 participated in the present study. The diagnosis of HP was established based on clinical data concerning the exposition to organic allergens, symptoms of disease developing as a result of contact with allergen, characteristic pattern of changes in HRCT, and lymphocytosis in BAL exceeding $30 \%$. The data concerning the exposition was documented in medical history of patient as a result of face to face interview, and collected retrospectively by the authors. In case of diagnostic difficulties, the lack of exposition, non-characteristic HRCT pattern, or lack of lymphocytosis in BAL, lung biopsy was performed. The details of HP diagnostic pathway in the presented group of patients, have been described previously [11].

The control group consisted of 102 patients, 61 males, 39 females, median age 65 years (range, 23-95 years), with various interstitial lung diseases, other than HP: 33 with idiopathic pulmonary fibrosis, 17 with ILD in the course of collagen tissue disease, 13 with sarcoidosis, 7 with non-specific interstitial pneumonia, 6 with cryptogenic organizing pneumonia, 5 with desquamative interstitial pneumonia, 2 with respiratory bronchiolitis interstitial lung disease, and 19 with chronic fibrotic lung disease not classified.

Patients' sera were obtained before the treatment. The tests were performed on fresh sera stored for maximum of 4 days at $2-8^{\circ} \mathrm{C}$. The study included antigens of thermophilic actinomycetes and protein antigens from birds' droppings prepared in our laboratory for internal use and validated in the past.

Assessment of antibodies to various organic antigens was performed by double diffusion in agar gel using Ouchterlony method. Antigens of thermophilic actinomycetes (Ervinia herbicola, Thermoactinomyces vulgaris, Thermopolyspora polyspora) and protein antigens from birds' droppings (pigeons, hens, ducks, parrots, turkeys) were applied to separate wells on agar gel located at a distance of $1 \mathrm{~cm}$ from the central well containing the tested serum. The plates were incubated for 5-7 days at $27^{\circ} \mathrm{C}$, then washed in physiological saline solution for 6 days. Next, the agar gels were dried at room temperature for 48 hours and stained in $0.1 \%$ light 
Table 1. Results of precipitins measurement in $128 \mathrm{HP}$ patients comparing to control group of patients with other interstitial lung diseases (102 patients)

\begin{tabular}{|c|c|c|c|}
\hline Examined group & $n$ & $\begin{array}{c}\text { Positive precipitins } \\
n(\%)\end{array}$ & $\begin{array}{c}\text { Negative precipitins } \\
n(\%)\end{array}$ \\
\hline HP patients & 128 & $73(57)$ & \\
\hline Exposed to birds antigens and/or thermophilic bacteria & 98 & $60(61)$ & $38(39)$ \\
\hline Not exposed to birds antigens and thermophilic bacteria & 30 & $13(43)$ & $17(57)$ \\
\hline Control group of ILD & 102 & $7(7)$ & $93(91)$ \\
\hline
\end{tabular}

Table 2. Results of precipitins measurement according to declared exposure to various birds' species in 128 hypersensitivity pneumonitis patients

\begin{tabular}{|c|c|c|c|c|c|}
\hline Type of exposure & $n$ & $\begin{array}{c}\text { Any anti-avian } \\
\text { precipitins } \\
n(\%)\end{array}$ & $\begin{array}{c}\text { Precipitin to same } \\
\text { species as exposed } \\
\qquad n(\%)\end{array}$ & $\begin{array}{c}\text { Precipitins to } \\
\text { other species than } \\
\text { exposed } \\
n(\%)\end{array}$ & $\begin{array}{c}\text { Negative result } \\
\text { of precipitin test } \\
n(\%)\end{array}$ \\
\hline Parrots & 10 & $8(80)^{*}$ & $4(40)$ & $4(40)$ & $2(20)$ \\
\hline Pigeons & 29 & $22(76)^{*}$ & $14(48)$ & $8(28)$ & $7(24)$ \\
\hline Poultry & 54 & $29(54)^{* * *}$ & $24(44)$ & $5(9)$ & $25(36)$ \\
\hline Any exposure & 77 & $49(64)$ & & & $28(36)$ \\
\hline Unproved exposure & 51 & $18(35)^{\#}$ & & & $33(65)$ \\
\hline
\end{tabular}

green solution. The test results were read after 24 hours: positive result - visible precipitation lines (antigen-antibody complexes), negative result - no precipitation lines (Fig. 1). The results of precipitins serology were compared with the data concerning exposition.

Statistical analysis: The variables were presented as numbers or percentages of positive results. Chi-square test was used to compare the number of positive results in different groups of patients.

The publication of the results of the study was approved by the Bioethical Committee, National Research Institute of Tuberculosis and Lung Diseases, No 14/2019.

\section{Results}

Medical history confirmed the exposition to various birds' allergens in 77/128 (60\%) of HP patients. Exposure to pigeons was reported by 29 patients: 15 pigeon breeders, 9 families of pigeon breeders, 3 nearest neighbors of pigeon breeders, 2 persons working on reconstructions of roofs and attics. Exposure to parrots (10 patients) concerned the parrot home breeders.

Occupational exposure to poultry proteins was documented in 54 patients living in the farms and breeding the different types of poultry. No data concerning the number of birds in the flocks were available. The data concerning feather duvet or down jackets have not been reported by our patients.
Positive precipitins to any of above mentioned organic antigens were obtained in 73 out of 128 of all HP patients (57\%) and in $61 \%$ of those exposed to such antigens (Table 1). Positive results in the control group were obtained in 7 out of 102 patients $(7 \%)$. Sensitivity of $\mathrm{ssIgG}$ in the whole HP group was 0.57 , in the persons with positive exposure 0.61 , and with specificity 0.93 .

Precipitins to at least one bird antigen was confirmed in 49 out of $77 \mathrm{HP}$ patients exposed to birds (64\%) (Table 2). The percentage of cases with serologic confirmation of ssIgG presence was significantly higher in case of contact with parrots of pigeons (80\% and $76 \%$, respectively) comparing to poultry $(54 \%), p=0.02$. However, the accordance rates between specific precipitins to parrots, pigeons, and poultry, and the exposition to those species were very similar (40\%, 48\%, and 44\%, respectively). Positive precipitins despite unproved exposure to birds were found in $35 \%$ of HP patients ( mostly to multiple birds' species).

The exposition to hay or hay products was confirmed in 63 out of 128 patients (49\%), significantly more frequently in males comparing to females, $p=0.0015$ (Table 3). Positive precipitins to thermophilic bacteria were found in $29 \%$ of exposed patients only (Table 4).

Precipitins to both birds antigens and thermophilic bacteria were found in 16 patients, among them 9 declared exposure to both avian proteins and hay compounds, 6 patients declared exposure to hay compounds, and 1 declared the exposure to avian proteins. 
Table 3. Exposure to hay and hay products according to gender in 128 hypersensitivity pneumonitis patients

\begin{tabular}{lccc}
\hline Gender & $\boldsymbol{n}$ & $\begin{array}{c}\text { Positive exposure } \\
\boldsymbol{n}(\boldsymbol{\%})\end{array}$ & $\begin{array}{c}\text { Negative exposure } \\
\boldsymbol{n}(\boldsymbol{\%})\end{array}$ \\
\hline Males & 63 & $40(64)^{*}$ & $23(36)$ \\
\hline Females & 65 & $23(35)^{* *}$ & $42(65)$ \\
\hline Total & 128 & $63(49)$ & $65(51)$ \\
\hline Difference between ${ }^{*}$ and $^{* *} p=0.0015$ &
\end{tabular}

\section{Discussion}

According to published recommendations, the most important problem in HP diagnostics is the confirmation of contact with organic allergens [5, 8]. We confirmed the exposition to birds' antigens in $60 \%$ of HP patients, to hay or hay products in $49 \%$, and to any of above mentioned antigens in $77 \%$ of patients. These data are in agreement with observations from other studies where birds' antigens were responsible for the most HP cases in their series [12, 13].

The role of precipitins to specific organic antigens in the diagnostic algorithm of HP is still under debate [14, 15]. Positive precipitins are found in 40-60\% of exposed healthy persons, indicating the immunization state [10, $14,16]$. The development of immune complexes mediated lung disease, with various degree of fibrosis, depends probably on many interfering factors as well as genetic predisposition [17].

Therefore, the role of ssIgG in HP diagnostic algorithm should be investigated only in patients with clinical and radiological signs of HP.

The present study revealed the presence of ssIgG in $57 \%$ of all HP patients, and in $61 \%$ of those exposed to birds' dropping and/or hay and hay products. In the control group of patients with ILDs other than HP, positive results of ssIgG were found in $7 \%$. Thus, the sensitivity of precipitins in the whole group was 0.57 and in the exposed group 0.61 , with the specificity of 0.93 comparing to non-HP ILDs.

The results of other authors' indicate that sensitivity of ssIgGs in HP may depend on clinical characteristics of the patients and the methods used. Suhara et al. documented ssIgG sensitivity of $0.8-1.0$ in acute bird-related HP, and 0.26-0.79 in chronic bird-related HP [18]. Simpson et al. reported that ELISA test showed greater sensitivity comparing to double immunodiffusion method [19]. Specificity of the test depends on the type of population included in the control group. The results obtained with the same type of assay as used in our study, in healthy persons not exposed to pigeons, revealed $9 \%$ of positive ssIgG against pigeons droppings [20]. Recently, Giaconi et al. investigated 108 patients with chronic fibrosing ILD and found 0.68 specificity of ssIgG for the recognition of HP [21].
Table 4. Results of precipitins to thermophilic bacteria according to declared exposure to hay or hay products in 128 hypersensitivity pneumonitis patients

\begin{tabular}{lccc}
\hline Exposure & $\boldsymbol{n}$ & $\begin{array}{c}\text { Positive precipitins } \\
\boldsymbol{n}(\boldsymbol{\%})\end{array}$ & $\begin{array}{c}\text { Negative precipitins } \\
\boldsymbol{n}(\boldsymbol{\%})\end{array}$ \\
\hline Positive & 63 & $18(29)$ & $45(71)$ \\
\hline Negative & 65 & $4(6)$ & $61(94)$ \\
\hline Total & 128 & $22(17)$ & $106(83)$ \\
\hline
\end{tabular}

In our study group, an important observation concerned patients with unproved contact with birds' allergens in whom ssIgG were positive (35\%) mostly to poultry and pigeons. According to other studies, ssIgG presence in HP patients denying the contact with birds' allergens may serve as a proof of exposition [22-24]. One of neglected by patients forms of exposition to birds' allergens is the contact with feather filling of pillows and clothing (feather duvet lung) [25]. The data concerning feather duvet or down jackets have not been reported by our patients; however, this type of information could be missed due to retrospective character of data collection.

We did not confirm the allergy to thermophilic actinomycetes in most of our patients who reported the exposition to hay or hay products. The data from literature indicate that farmer's lung may be caused either by thermophilic bacteria or by molds [10, 24, 26, 27]. Molds can induce farmer's lung in large agriculture regions, especially during wet and warm seasons [24]. Most frequently involved are Alternaria, Aspergillus, and Botrytis species [24], and in some geographic regions, Absidia (Lichtheimia corymbifera) and Wallemia were suggested as the cause of farmer's lung disease [26, 27]. As molds' antigens were not included in our laboratory set, this type of allergy could be missed out in our material.

Identification and eradication from patient's environment, the antigen responsible for HP pathogenesis, is essential for the treatment and management of HP. The presence of precipitins to specific organic antigens indicate dependable contact of the patients with certain organic substances and enables their elimination from the environment.

\section{Conclusions}

Positive precipitins were obtained in 57\% of all HP patients and in $61 \%$ of those exposed to above mentioned antigens. Positive results in the control group were obtained in $7 \%$ of patients. Sensitivity of ssIgG in HP group were 0.57 , and specificity 0.93 .

Positive serology to birds' antigens was confirmed in $64 \%$ of HP patients who have the contact with birds, significantly more often in those exposed to parrots and pigeons comparing to those exposed to poultry. 
The comparison of ssIgG with exposition data indicated the possibility of cross reactivity between various avian antigens.

Positive avian serology was confirmed in $35 \%$ of HP patients with unproved exposure to birds antigens; this information might be important in HP diagnostic algorithm and management of HP.

Precipitins to thermophilic bacteria were found in $29 \%$ of HP patients exposed to hay or hay products. Low-rate of confirmation of farmer's lung with precipitins in our material may be caused by lack of mold antigens in our testing probes.

\section{The authors declare no conflict of interest.}

\section{References}

1. Hyldgaard C, Hilberg O, Muller A, Bendstrup E (2014): A cohort study of interstitial lung diseases in central Denmark Respir Med 108: 793-799.

2. Cottin V, Hirani NA, Hotchkin DL, et al. (2018): Presentation, diagnosis and clinical course of the spectrum of progressive-fibrosing interstitial lung diseases. Eur Respir Rev 27: 180076.

3. Fernandez Perez E, Kong A, Raimundo K, et al. (2018): Epidemiology of hypersensitivity pneumonitis among an insured population in the United States: a claims-based cohort analysis. Annals ATS 15: 460-469.

4. Szafrański W (2012): Analiza grupy chorych na śródmiąższowe choroby płuc hospitalizowanych w latach 2000-2009 na oddziale płucnym wojewódzkiego szpitala w Radomiu. Pneumonol Alergol Pol 80: 523-532.

5. Vasakova M, Morell F, Walsh S, et al. (2017): Hypersensitivity pneumonitis: perspectives in diagnosis and management. Am J Respir Crit Care Med 196: 680-689.

6. Salisbury ML, Gross BH, Chughtai A, et al. (2018): Development and validation of radiological diagnosis model for hypersensitivity pneumonitis. Eur Respir J 52: 1800443.

7. Wojtan P, Mierzejewski M, Osińska I, Domagała-Kulawik J (2016): Macrophage polarization in interstitial lung diseases. Cent Eur J Immunol 41: 159-164.

8. Salisbury ML, Myers JL, Belloli EA, et al. (2017): Diagnosis and treatment of fibrotic hypersensitivity pneumonia. Where we stand and where we need to go. Am J Respir Crit Care Med 196: 690-699.

9. Churg A, Bilawich AM, Wright JL (2018): Pathology of chronic hypersensitivity pneumonitis. What is it? What are the diagnostic criteria? Why do we care? Arch Pathol Lab Med 142: 109-119.

10. Morell F, Villar A, Ojanguren I, et al. (2016): Hypersensitivity pneumonitis: challenges in diagnosis and management, avoiding surgical lung biopsy. Semin Respir Crit Care Med 37: 395-405.

11. Szturmowicz M, Barańska I, Jędrych ME et al. (2019): Hypersensitivity pneumonitis recognised in single pulmonary unit, between 2005 and 2015, comparison with recently proposed diagnostic criteria. Adv Respir Med 87: 83-89.
12. Kumar R, Singh M (2015): Bird fancier's lung: clinical-radiological presentation in 15 cases. Pneumonol Alergol Pol 83: 39-44.

13. Sema M, Miyazaki Y, Tsutsui T, et al. (2018): Environmental levels of avian proteins are relevant to the progression of chronic hypersensitivity pneumonitis during antigen avoidance. Immun Inflamm Dis 6: 154-162.

14. Morisset J, Johannson KA, Jones KD, et al. (2018): Identification of diagnostic criteria for chronic hypersensitivity pneumonitis. An International Modified Delphi Survey. Am J Respir Crit Care Med 197: 1036-1044.

15. Woge MJ, Ryu JH, Moua T (2017): Diagnostic implications of positive avian serology in suspected hypersensitivity pneumonitis. Respir Med 129: 173-178.

16. Jędrych ME, Szturmowicz M, Bestry I, Kuś J (2016): Hypersensitivity pneumonitis: Diagnostic criteria, treatment, prognosis and prevention. Med Pr 67: 517-527.

17. Kiszałkiewicz J, Piotrowski W, Brzeziańska-Lasota E, et al. (2017): Signalling pathways and their miRNA regulators involved in the etiopathology of idiopathic pulmonary fibrosis (IPF) and hypersensitivity pneumonitis (HP). Adv Respir Med 85: 164-178.

18. Suhara K, Miyazaki Y, Okamoto T, et al. (2015): Utility of immunological tests for bird-related hypersensitivity pneumonitis. Respir Investig 53: 13-21.

19. Simpson C, Shirodaria PV, Evans JP, et al. (1992): Comparison of immunodiffusion and enzyme-linked immunosorbent assay in the detection of abnormal antibodies in pigeon breeder's disease. J Clin Pathol 45: 490-493.

20. Meleniewska-Maciszewska A (1980): Przydatność antygenów wyizolowanych z wydalin gołębi do prób serologicznych w rozpoznawaniu AZPP u hodowców gołębi. Pneumonol Pol 48: 609-617.

21. De Giacomi F, Andreano A, Faverio P, et al. (2017): Utility of precipitating antibody testing in the diagnostic evaluation of chronic hypersensitivity pneumonia. Sarcoid Vasc Diffuse Lung Dis 34: 149-155.

22. Salisbury ML, Gu T, Murray S, et al. (2019): Hypersensitivity pneumonitis radiologic phenotypes are associated with distinct survival time and pulmonary function trajectory. Chest 155: 699-711.

23. Morisset J, Johannson KA, Vittinghoff E, et al. (2017): Use of mycophenolate mofetil or azathioprine for the management of chronic hypersensitivity pneumonitis. Chest 151: 619-625.

24. Nogueira R, Melo N, Novais e Bastos H, et al. (2019): Hypersensitivity pneumonitis: antigen diversity and disease implications. Pneumonol 25: 97-108.

25. Koschel D, Luetzkendorf L (2010): Antigen specific IgG antibodies in feather duvet lung. Eur J Clin Invest 40: 797-802.

26. Millon L, Roussel S, Rognon B, et al. (2012): Aspergillus species recombinant antigens for serodiagnosis of farmer's lung disease. J Allergy Clin Immunol 130: 803-805.

27. Rognon B, Reboux G, Roussel S, et al. (2015): Western blotting as a tool for the serodiagnosis of farmer's lung disease: validation with Lichtheimia corymbifera protein extracts. J Med Microbiol 64: 359-368. 